\title{
Research on the HR Risk Management System of Innovative Start-up Companies under the Internet Plus Background
}

\author{
Zhang Yong \\ Wuhan Business University, Wuhan, 430056, China \\ E-mail: 5880161@qq.com
}

Keywords: Internet Plus; Innovative start-up companies; HR risk management

\begin{abstract}
This paper focuses on the study of the HR (Human Resources) Risk Management System for innovative start-up companies under the background of Internet Plus. Firstly, a review of relative researches of HR management at home and abroad is presented, followed by a summary of the basic definitions, contents and characteristics of risk management and HR management. Next, the establishment of HR Risk Management System for innovative start-up companies under the background of Internet Plus is discussed from four aspects: risk identification, risk assessment, risk prevention and control and dynamic monitoring. Then, based on these discussions, this paper illustrates risk factors and their consequences of entrepreneurial HR management. Finally, with innovative start-up companies as its research object, it puts forward countermeasures for prevention and control of risks in HR management, which is useful to promote the healthy and smooth development of HR in innovative start-up companies.
\end{abstract}

\section{Introduction}

In an era of Internet, the popularity of computer science and the widespread use of Internet tools have laid a broad foundation for the rise and development of big data. [1] The Internet has also brought new opportunities for corporate HR management. However, at present, the application of the Internet in China is still in its infancy, and the most mentioned field is only marketing. Enterprises are still facing grave challenges in terms of how to apply the relevant principles and concepts of the Internet to the field of HR and improve the efficiency of corporate HR management. Enterprises will have to embrace risks and challenges in HR management if they want to obtain greater social effectiveness. [2] Therefore, it is important to research more on risk identification and control of corporate HR management to improve the competitiveness of enterprises.

\section{Definition and Characteristics of HR Risk Management}

\subsection{Definition of HR Risk Management}

The earliest concept of risk was proposed by Western classicists in the 19th century. They held the opinion that business operations create a kind of byproduct - risk which is based on the operator's business activities in which remuneration is generated. Knight, an American economist, gave a rather classic definition of risk in 1921. [3] He believes that risk is a kind of predictable uncertainty, which refers to that although the economic entity is not defined sufficiently, a probability value can be given for each situation that may occur in the future. Takei Hiratsuka, a Japanese scholar put forward a new view of risk based on his understanding and analysis of the results of previous scholars. [4] He believes that risk is a natural change in a given environment and period of time, resulting in economic loss. [5] This definition includes three aspects: first, risk exists objectively; second, differences occur between risk and uncertainty; third, risks can be identified and measured. According to the definition of risk above, risk management is the process of identifying, estimating, evaluating, and controlling risks in a certain way. 


\subsection{Contents of Characteristics of HR Risk Management of Innovative Start-up Companies}

The risk of corporate HR management refers to that due to influences of internal or external environment of the HR, the results of various management activities which consists of HR may deviate from the expected goals. The risks of corporate HR management are throughout the entire process and also appear in specific segments of HR management in innovative startups. For example, in the process of employee recruitment, training, management, job design analysis and performance appraisal, some specific management risks may appear more or less. Therefore, companies must take effective measures to prevent potential risks in management activities. To achieve this, it is necessary to start with risk management activities, and then reduce the losses caused by HR risk management by means of risk identification, risk assessment, risk prevention and management and other management activities.

\subsection{Characteristics of HR Risk Management of Innovative Start-up Companies}

(1) Mobility

The mobility of HR risk management in innovative startups mainly refers to the mobility of employees. The human resources that companies rely on are concentrated on people who themselves have extremely strong liquidity, so the risks are full of mobility, too. The loss of important employees will have a significant impact on the company and hinder its development. Therefore, corporate HR risk management should pay attention to employees’ mobility.

(2) Positive Correlations

The positive correlations of the HR management mean that HR of innovative start-up enterprises needs investment. The greater the investment is, the greater the risks will come up. In general, powerful companies will pay more for HR training and employees' payment, which means higher costs. Once the risk of employee loss arises, greater losses can be caused than ordinary companies. In addition, within the company, higher-level personnel need more salary and training time than those on the bottom-level. Thus, once they resign, they will also bring greater risks.

(3) Protracted Nature

HR risk management in innovative start-up companies is a long-term process which will not see outcomes in the short term. For example, it is common that some large-scale enterprises carry out planning and renewal of HR day after day and hold job fairs in universities to enhance corporate image. But if managing corporate HR management in an inappropriate way, the enterprises will face greater risks, leading to more difficulties in long-term HR management.

(4) Solvability

Innovative start-up enterprises are unable to resist losses caused by changes in the external environment such as politics, economy, and law. What they only can do is to respond quickly, make some adjustments, and adopt appropriate measures to adapt to changes of external environment and reduce risks. Firstly, if the loss is caused by the company, then the risk is lurking in the enterprise itself. Secondly, since it is implemented by the personnel engaged in HR management, their understanding of policies and ability will directly affect the degree of risk. Thirdly, it is possible to resist risks of HR management. As long as the development plan is in line with reality, the system reasonable, the management strict, and the implementation in place, it is possible to resolve the risks.

(5) Dynamism

The frequency of occurrence of risks of innovative start-up enterprises, the scopes and level of influences are all different and dynamic. The dynamism of risks increases difficulties of risk management, which requires flexible management methods to remain changes and avoid rigidity.

(6) Destructiveness

HR of innovative start-up enterprises are the core of a company. Once a risk occurs, the losses to the company can be enormous. It not only does harm to the safety of the company's material resources, but may even result in the complete failure of a company's development strategy. 


\section{Construction of HR Risk Management System of Innovative Start-up Companies under Internet Plus Background}

The construction of HR Risk Management System of innovative start-up companies under Internet plus background refers to the prevention of risks through a series of comprehensive activities such as risk identification, evaluation, prevention and control, and dynamic monitoring. This usually reduces the harm caused by risks and the probability of risk, and at the meantime it identifies the source of risk, finds the root of risks, and fundamentally solves the problem. The corporate HR risk management generally includes job analysis, employee recruitment, training mechanism, career planning, payment management, welfare mechanisms, and etc. The specific process is shown in Figure1.

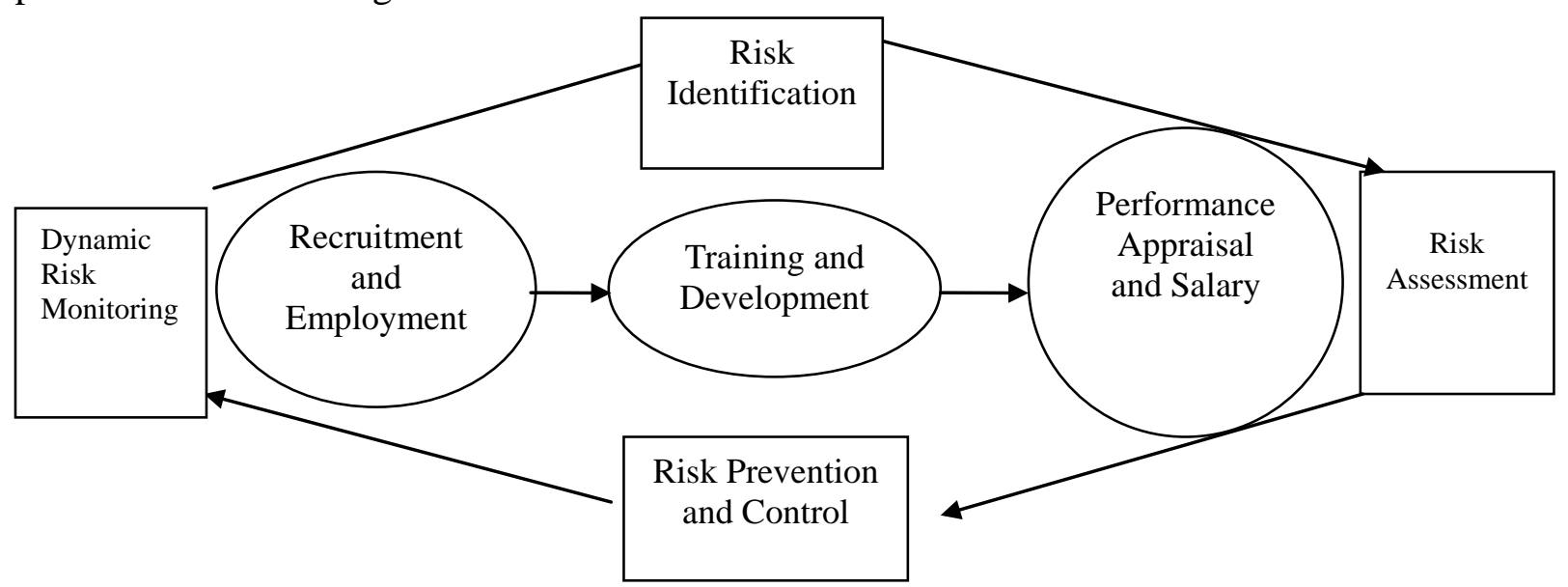

Figure1- Construction of HR Risk Management System of Innovative Start-up Companies under Internet Plus Background

\subsection{Identification of Risks}

The identification of the risks referred to in this paper is an automatic search for potential risks so that they can be controlled timely. The main approach is to find the source of HR management risks through questionnaires and theoretical analysis, and then calculate the probability of converting the risk into an accident and analyze the necessary conditions for risk transformation. According to the analysis of these conditions, the key is to add crisis prevention in the process of the chain reaction between them to control the transformation of risks and reduce the probability of accidents and the degree of harm.

\subsection{Risk Assessment}

Risk assessment aims at the prevention and control with optimal countermeasures to achieves the safety of HR management of enterprises by using scientific theories and mathematical researches. Quantitative analysis of the probability of HR management risks and the harms that may occur after the risks will be given in risk assessment. The process is generally as follows: first, establish the goal of risk assessment; next found a comprehensive index system for risk assessment and select the method and model to be applied for risk assessment; then implement a comprehensive assessment and analyze the results, and finally make an effect evaluation of preventive measures.

\subsection{Static control of risk}

The static prevention and control of risks refers to the prevention and control of risks. The main steps are: First, conduct further investigations on the results of the assessment, usually by means of questionnaire and expert assessment; and then put forward a proposed prevention and control plan based on the results of the investigation and assessment on HR, discusses the proposed plan with experts about its feasibility, and report it to the superior for approval, and finally implement risk prevention measures and evaluate the effectiveness of risk prevention to reduce the serious damage to HR management after the occurrence of the risk. 


\subsection{Dynamic Monitoring of Risk}

Dynamic monitoring of risks means that after the old risks are eliminated, new risks will appear from time to time, which requires that the Risk Management System can monitor the risks of HR management in real time. Therefore, the three previous steps must also be carried out continuously. As a result, an uninterrupted risk prevention and control system will be formed to more effectively resolve various risks in HR management. This can effectively reduce damages, and promote the healthy and rapid development of the company.

\section{Conclusions}

This research has targeted the history and current status of HR risk management at home and abroad, and discusses the basic concepts, contents and characteristics of HR risk management in innovative start-up enterprises. The theoretical system of HR risk management for innovative start-up enterprises is still not perfect. In particular, the research on innovation-based entrepreneurial HR Risk Management System is not comprehensive and profound. The study of this paper hopes to further analyze the construction of the HR Risk Management System in innovative entrepreneurial enterprises under the background of Internet Plus, so that some research gaps in current theory can be filled.

\section{Acknowledgements}

In this paper, the research was sponsored by Wuhan Business University, and the Project Name is Research on the HR Risk Management System of Innovative Start-up Companies under the Internet Plus Background (Project No. B2016360).

\section{References}

[1] "Employing the components of the human development index to drive resources to educational policies". Sant’’Anna, A.P, Ribeiro, R. O. A, Dutt Ross, S. Social Indicators Research. 2011

[2] The Datafication of Human Resources. Josh Bersin. Forbes. com. 2013

[3] How organizational climate and structure affect knowledge management-The social interaction perspective[J] . Chung-Jen Chen, Jing-Wen Huang. International Journal of Information Management. 2006 (2)

[4] Human resource performance index in TQM environment. Sandeep Grover, V. P. Agrawal, I. A. Khan. International Journal of Management Practice. 2005

[5] Accountability in Human Resource Management. Jack J Phillips. 1996 